\title{
Production of antibodies to staphylococcal superantigens in atopic dermatitis
}

\author{
D E Campbell, A S Kemp
}

\begin{abstract}
Staphylococcal superantigens (SAG) are implicated in the inflammation of atopic dermatitis. As SAG mediated diseases may be modified by specific antibodies, the antibody response to SAG in atopic dermatitis was investigated. Immunoglobulin (Ig) G to staphylococcal enterotoxin A (SEA), staphylococcal enterotoxin B (SEB), and toxic shock syndrome toxin 1 (TSST-1) were measured by sandwich enzyme linked immunosorbent assay (ELISA) in 74 children with atopic dermatitis and 111 controls. Controls had detectable IgG to SEA, SEB, and TSST-1, which increased with age. Atopic dermatitis subjects had an increased response to SEB at 6 months to 2 years $(76 \% v 42 \%)$ and 2 to 7 years $(79 \% \quad v \quad 57 \%)$, and equivalent responses to SEA and TSST-1, compared to controls. It is suggested that increased responses to SEB relate to increased colonisation and hence exposure to superantigen producing staphylococcus in atopic dermatitis, and that inflammation of atopic dermatitis is not caused by an inability to make antibody to SAG.

(Arch Dis Child 1998;79:400-404)
\end{abstract}

Keywords: atopic dermatitis; staphylococcus; superantigen; antibody

Superantigens are particular antigens capable of inducing massive $\mathrm{T}$ cell activation caused by their ability to bind multiple $\mathrm{T}$ cell receptors in an antigen non-specific manner. ${ }^{1}$ Staphylococcal superantigens (SAG) are potent toxins produced by particular strains of Staphylococcus aureus. Stimulation of $\mathrm{T}$ cells by SAG is considered to trigger diseases such as staphylococcal toxic shock syndrome ${ }^{2}$ and staphylococcal food poisoning, ${ }^{34}$ and has been implicated in other disorders such as Kawasaki disease ${ }^{56}$ and atopic dermatitis. ${ }^{78}$ Recently, it has been shown that specific antibody to superantigens may be protective against superantigen mediated disease. For example, susceptibility to toxic shock syndrome has been correlated with lack of pre-existing antibody to toxic shock syndrome toxin 1 (TSST-1)..$^{10}$

Children with atopic dermatitis have very high rates $(60-90 \%)$ of superantigen producing staphylococci colonisation of their skin. ${ }^{7}$ It is likely that this colonisation plays a role in the pathogenesis and inflammatory responses in atopic dermatitis. Indirect evidence for such a role is illustrated by the clinical improvement of atopic skin lesions after antistaphylococcal treatment. ${ }^{11}{ }^{12}$ Furthermore, application of sta- phylococcal enterotoxin B (SEB) to intact skin has been shown to induce lesions which clinically and histologically resemble atopic dermatitis. ${ }^{13}$

We have previously shown that children with atopic dermatitis have a deficient cell mediated immune response to SAG, with greatly reduced interferon $\gamma$ (INF $\gamma$ ) production following in vitro stimulation with SEB. ${ }^{14}$ Similar reductions in cell mediated immunity to SAG have also been reported in adults with atopic dermatitis. ${ }^{15}$ Although there is some information on antibody responses to SAG in normal children, ${ }^{17}{ }^{18}$ the production of immunoglobulin (Ig) $G$ antibodies in atopic dermatitis has not been described. It is possible that subjects with atopic dermatitis would exhibit increased responses either because of their cutaneous colonisation or because of immune deviation to a Th2 (antibody producing) type response. Alternatively atopic subjects may exhibit reduced antibody responses, in addition to the previously demonstrated reduction in cell mediated immunity to SAG. A decreased capacity for antibody production could make children with atopic dermatitis more prone to superantigen producing $S$ aureus colonisation. To examine these questions we measured serum IgG antibody to SEB, staphylococcal enterotoxin A (SEA), and TSST-1 from children with atopic dermatitis, from nonatopic children, and young adults.

\section{Methods}

SUBJECTS

Sera from 74 children with mild to moderate or severe atopic dermatitis, classified according to the criteria of Hanifin and Rajika, ${ }^{19}$ were collected from children having blood taken as part of the investigation and management of their atopic dermatitis. Ethics approval for experiments and blood collection from children with atopic dermatitis was obtained from the Royal Children's Hospital Research Foundation ethics committee. Samples were obtained from 44 boys and 30 girls (ratio male: female, 1.5:1). The mean $\operatorname{IgE}$ of the subjects was $4433 \mathrm{IU} / \mathrm{ml}(60-54296 \mathrm{IU} / \mathrm{ml})$. The majority of the samples came from Caucasian children $(n=61)$ with the remainder of samples from Asian children $(n=13)$. There were 33 children with atopic dermatitis aged 6-24 months, 24 aged 2-7 years, and 17 aged 8-16 years. Sera from 111 child and young adult controls were obtained from samples sent to our laboratory for evaluation of immunoglobulins, antinuclear antibodies, complement and/or antigliadin antibodies, where IgE was in the normal range for age: $<6 \mathrm{IU} / \mathrm{ml}(0-0.2$ 
years), < $45 \mathrm{IU} / \mathrm{ml}(0.2-0.5$ years $),<20 \mathrm{IU} / \mathrm{ml}$ (0.5-0.7 years), < $25 \mathrm{IU} / \mathrm{ml}(0.7-1$ years), $<35 \mathrm{IU} / \mathrm{ml}$ (1-2 years), < 130 (2-4 years), $<150 \mathrm{IU} / \mathrm{ml}$ (4-7 years), < $200 \mathrm{IU} / \mathrm{ml}$ (> 7 years), and the requested test was negative. IgE was measured using Quanticlone IgE radioimmunoassay (Kallestad Diagnostics Inc, Chaska, Minnesota, USA) according to the manufacturer's instructions, with a sensitivity of $5 \mathrm{IU} / \mathrm{ml}$.

Age ranges were examined in groups: 6-24 months, $2-7$ years, $8-16$ years, and more than 16 years. Infants below 6 months were not included because of the possibility of persistent maternal antibody. Serum was stored at $-20^{\circ} \mathrm{C}$ until assayed.

ELISA FOR TSST-1, SEB, SEA

TSST-1, SEB, and SEA antibodies were measured by sandwich enzyme linked immunosorbent assay (ELISA). High binding plates were coated with $100 \mu 1$ /well of TSST-1, SEB, and SEA (Sigma Chemical Co, St Louis, Missouri, USA) at $1 \mu \mathrm{g} / \mathrm{ml}$ in carbonate buffer, $\mathrm{pH}$ 9.6 , and incubated for 16 hours at $4^{\circ} \mathrm{C}$. Plates were washed with phosphate buffered saline (PBS)/Tween, blocked with $1 \%$ gelatin/PBS/ Tween for two hours and washed a further four times. Samples $(100 \mu 1 /$ well $)$ were added at $1: 1000$ ( $1 \%$ gelatin/PBS/Tween) and incubated at $37^{\circ} \mathrm{C}$ for 90 minutes. Biotinylated monoclonal antihuman IgG (Pharmingen, San Diego, California, USA) $100 \mu \mathrm{l} /$ well $(0.5 \mu \mathrm{g} /$ $\mathrm{ml}$ ) was added, incubated at room temperature for 45 minutes, washed, and avidin peroxidase diluted at 1:400 (100 $\mu \mathrm{l} /$ well) was then added and incubated at room temperature for a further 30 minutes. After final washing $100 \mu \mathrm{l} /$ well of 3,3',5,5'-tetra-methyl benzidine substrate (KPL Laboratories, Gaithersburg, Maryland, USA) was added and reaction stopped by addition of $100 \mu \mathrm{l} /$ well of $2 \mathrm{M}$ $\mathrm{H}_{2} \mathrm{SO}_{4}$. Colour was read at $450 \mathrm{~nm}$ (background $650 \mathrm{~nm}$ ).

All standards and samples were performed in duplicate. Optimal concentrations of coating superantigen and detection antibody were determined by set up checkerboard experiments. Pooled adult sera $(n=20)$, aliquoted and stored at $-70^{\circ} \mathrm{C}$, was used to construct a standard curve using doubling dilutions from 1:250. Arbitrary units of antibody were defined as pool $1: 1000=100$ laboratory units (LU). Concentrations of the samples $(1: 1000)$ were then calculated from the standard curve.

Interassay variability was $9 \%, 5.6 \%$, and $9.6 \%$ for TSST-1, SEB, and SEA assays, respectively. An uncoated pair of wells was included in all plates to assess non-specific binding. Lower limit of detection for each assay was calculated using Biomek software, and final lower limit of detection for TSST-1, SEB, and SEA assays was calculated by mean (2 SD) of lower limit of detection. These were 2.4 LU, 8.7 LU, and 2.1 LU for SEB, TSST-1, and SEA, respectively.

\section{STATISTICS}

Comparison of atopic and non-atopic age antibody concentrations were performed using

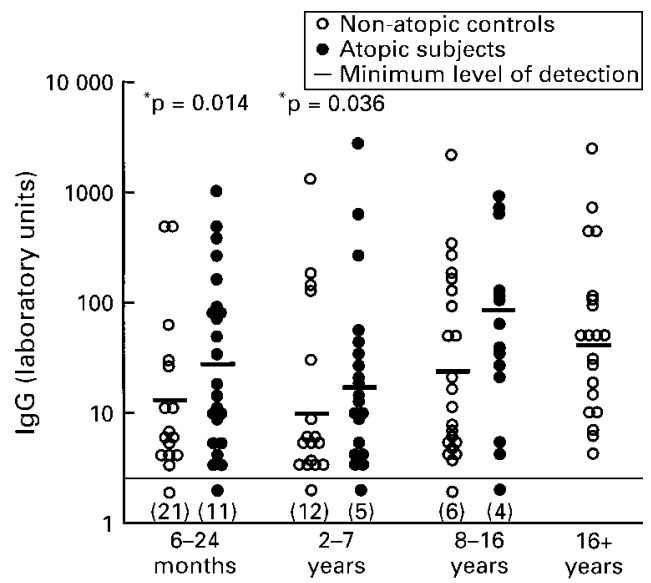

Figure 1 IgG SEB (laboratory units (LU)) from subjects with atopic dermatitis and non-atopic controls. Mean bar represents geometric mean. Numbers in parentheses are number of subjects below lower limit of detection.

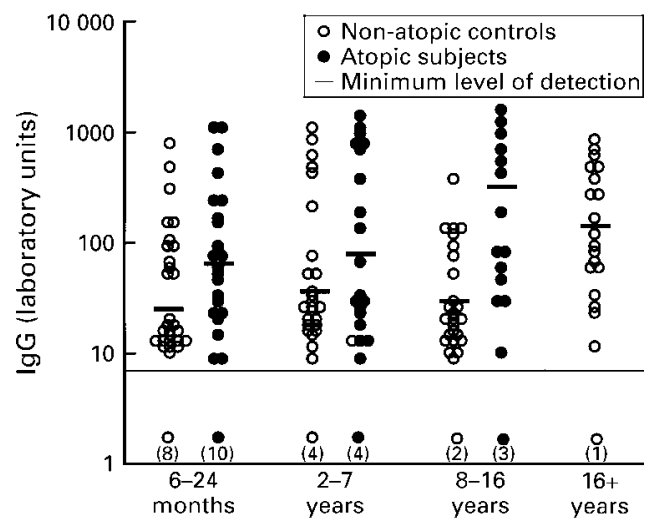

Figure 2 IgG SEA (laboratory units (LU)) from subjects with atopic dermatitis and non-atopic controls. Mean bar represents geometric mean. Numbers in parentheses are number of subjects below lower limit of detection.

Mann-Whitney non-parametric U test. Comparisons of detectable antibody production were performed using $\chi^{2}$ test.

\section{Results}

CONTROL NON-ATOPIC CHILDREN

A significant proportion of control children had detectable antibodies to one or more of SEA, SEB, and TSST -1 . The presence of these antibodies increased with age. Detectable antibodies to SEB were found in $42 \%, 57 \%, 78 \%$, and $100 \%$ of subjects in the age groups $6-24$ months, 2-7 years, 8-16 years, and more than 16 years, respectively (fig 1). Detectable antibodies to SEA rose from $78-95 \%$ (fig 2) and to TSST-1 rose from $69-100 \%$ (fig 3) over this age range. In subjects less than 16 years old antibodies to SEA and TSST-1 were more frequent than antibodies to SEB $(p<0.005$, $\mathrm{p}<0.005$, respectively). Young children $(6-24$ months) were capable of significant antibody production, with titres up to 10 -fold higher than adult pool in some cases. There was a trend for higher SEB antibody concentration (geometric mean) with increasing age. For all three superantigens the geometric mean of antibody was highest in those over 16 years.

There was no relation between TSST-1, SEB, and SEA IgG concentrations for each individual - that is, those children who made 


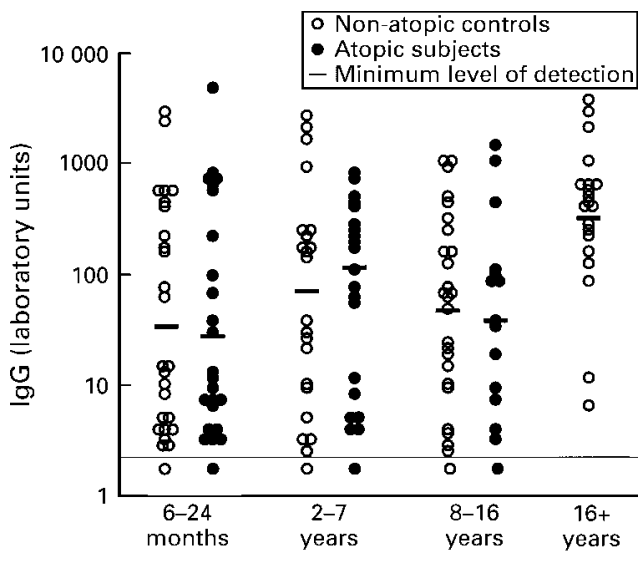

Figure 3 IgG TSST-1 (laboratory units (LU)) from subjects with atopic dermatitis and non-atopic controls. Mean bar represents geometric mean. Numbers in parentheses are number of subjects below lower limit of detection.

significant quantities of antibody to one superantigen did not tend to make more antibody to the other superantigens. The children with no antibody to all three superantigens were equally distributed in terms of age (data not shown).

CHILDREN WITH ATOPIC DERMATITIS

The proportion of children with moderate and severe atopic dermatitis producing antibodies to SAG was equal to or greater than that of controls. The proportion of children with atopic dermatitis and control children with detectable antibodies was similar for SEA and TSST-1 in all age groups. Infants (6-24 months) and children under 7 years with atopic dermatitis had a higher proportion of SEB antibody than controls $(p=0.03)$ (table 1$)$, with $67 \%$ of atopic infants (6-24 months) and $79 \%$ of atopic children (2-7 years), but only $42 \%$ (6-24 months) and $57 \%$ (2-7 years) of control children having detectable IgG to SEB. Furthermore, atopic children had higher concentrations of SEB IgG than control children both in the 6-24 month group $(\mathrm{p}=0.014)$, and the $2-7$ year group $(p=0.036)$ (fig 1$)$. There was no significant difference in the concentrations of SEA IgG or TSST-1 IgG between atopic and control children of any age. There was no correlation between serum IgE and concentration of SEA, SEB, or TSST-1 IgG in atopic subjects. There were no obvious clinical distinctions in the severity of the atopic dermatitis in those children who did not produce antibodies to any of the superantigens. Two of these children had mild to moderate atopic dermatitis, two had moderate atopic dermatitis, and one had severe atopic dermatitis.

Table 1 Percentage of detectable antibodies to SEB, SEA, and TSST-1 in subjects with atopic dermatitis (atopic) and non-atopic controls

\begin{tabular}{|c|c|c|c|c|c|c|}
\hline \multirow[b]{2}{*}{ Age } & \multicolumn{2}{|l|}{$S E B$} & \multicolumn{2}{|l|}{$S E A$} & \multicolumn{2}{|l|}{ TSST-1 } \\
\hline & Control & Atopic & Control & Atopic & Control & Atopic \\
\hline 6-24 months & 42 & 67 & 78 & 70 & 69 & 70 \\
\hline $2-7$ years & 57 & 79 & 86 & 83 & 75 & 83 \\
\hline $8-16$ years & 78 & 76 & 93 & 82 & 93 & 82 \\
\hline$>16$ years & 100 & - & 95 & - & 100 & - \\
\hline
\end{tabular}

\section{Discussion}

Our findings demonstrate that young infants are capable of producing antibody to SAG and indicate that exposure to SAG occurs frequently in the first years of life. As superantigens are proteins, this finding is consistent with previous reports that vigorous responses to other proteins are well established in the first year of life. ${ }^{20}$ It is not yet clear whether all infants have the capacity to make antibodies upon superantigen exposure. The finding that children with undetectable $\operatorname{IgG}$ to all three superantigens were equally distributed in age suggests that certain individuals may be hyporesponsive to SAG proteins in a non-age dependent manner.

The prevalence of specific antibodies to SAG in normal adults has been reported to range from $30-90 \% .^{21-24}$ There are several studies reporting the prevalence of SAG antibodies in normal children. ${ }^{25}$ In a survey of 168 children from Utah, $94 \%$ of TSST-1 producing $S$ aureus carriers and $33 \%$ of non-carriers were found to have TSST-1 antibody; other superantigen antibodies were not measured, however. In another study, $33 \%$ of Scandinavian subjects less than 10 years old but $88 \%$ over 10 years had detectable antibody to TSST $-1 .{ }^{18}$ In a small cohort of 22 control children from a study of Kawasaki disease ${ }^{26}$ the proportion of antibodies detected to TSST-1, SEA, and SEB was $45 \%, 27 \%$, and $27 \%$, respectively. These proportions are significantly less than we observed to SEB, SEA, and TSST-1 in children of similar ages. This may be caused by the increased sensitivity of our assay, as an amplification step using avidin peroxidase was included in our assay but not the previous study, and avidin peroxidase has been reported to enhance the sensitivity of sandwich ELISAs. ${ }^{27}$ As the controls in this study were undergoing laboratory investigations, it is also possible that they do not represent completely healthy children, although all the investigations requested were negative. Although this is a limitation of the study, it would be difficult to obtain this number of samples from completely healthy non-atopic children. Furthermore, the levels of antibody in these controls would likely have been equivalent or higher than those of "healthy controls", and thus the comparison of "healthy controls" with atopic children is likely to have given similar results to the present controls.

The prevalence of colonisation of normal subjects with various SAG producing strains within our study community are not known, although their prevalence has been examined elsewhere. Jacobson et al examined nasal carriage of superantigen producing $S$ aureus and simultaneous prevalence of detectable IgG to TSST- 1 in 168 children in the USA. ${ }^{25}$ They observed TSST-1 to be the most prevalent SAG identified, being present in $29 \%$ of $S$ aureus strains with a carriage rate of $9.5 \%$. SEA, B, C, and D were identified in only 6.5 , $3.0,1.2$, and $1.2 \%$ of $S$ aureus isolates, respectively. A lower carriage rate of $5 \%$ of superantigen producing $S$ aureus was observed by Hoeger et al in a group of normal children from 
Hamburg. ${ }^{7}$ Presumably constant carriage is not required for antibody production as these carriage rates are significantly less than the reported prevalence of antibodies to SAG. That exposure to these superantigens is ubiquitous at some time in childhood is suggested by our findings of very high rates $(95-100 \%)$ of antibody positivity in control subjects over 16 years of age.

There have been no previous studies of IgG antibodies to SAG in atopic dermatitis. We have shown that children with moderate and severe atopic dermatitis produce antibodies to SAG as effectively as non-atopic children, and conclude that their susceptibility to colonisation with superantigen producing $S$ aureus is unlikely to result from an inability to produce antibody against superantigens. Infants and young children with atopic dermatitis had higher titres and a greater prevalence of antibody to superantigen SEB. This could be caused by either immune deviation of the atopic subjects to a Th2 type antibody producing response or to increased exposure to SEB. As the proportion and titres of antibody to TSST-1 and SEA were not significantly increased compared with controls, which might be suspected if there were a general deviation of the immune response to a Th2 type, we suggest this increased antibody response is caused by higher levels of exposure because of increased colonisation. This suggests that colonisation with SEB producing pathogens may be more frequent than SEA or TSST-1 producing pathogens in our atopic subjects. The finding of high levels of anti-SEB antibody in atopic children under 7 years also suggests that early colonisation is occurring in the atopic children.

Rosten et al postulated that specific antibodies are important for combatting superantigen mediated disease on the basis of their findings of significantly lower TSST-1 IgG in acute serum from adults with toxic shock syndrome compared with controls. ${ }^{9}$ Our findings do not suggest that atopic dermatitis is prevented or lessened by increased antibody levels against SAG. Furthermore, the severity of the atopy as measured by serum IgE did not negatively correlate with concentrations of IgG SEA, SEB, or TSST -1 . We found that infants and younger children with atopic dermatitis had a greater proportion and higher concentrations of SEB IgG than did the non-atopic controls. If the acquisition of antibodies directed against superantigens lessened or prevented the development of atopic dermatitis, we would have expected titres to have been higher in control children. We have also found that pooled human immunoglobulin at physiological concentrations, which contains antibody against superantigens, did not inhibit the in vitro release of inflammatory mediators such as $\mathrm{TNF} \alpha$ and IFN $\gamma$ from lymphocytes stimulated with SEB (Campbell and Kemp, unpublished data). Thus both in vitro and the present in vivo findings do not suggest that antibody against SAG diminishes inflammation in atopic dermatitis.
We postulate that the diminished cell mediated immunity to $S$ aureus and SEB previously observed in children with atopic dermatitis ${ }^{14}$ results in an inability to eradicate $S$ aureus from the skin of atopic subjects, and that the increased titres of anti-SEB antibody we observed are caused by increased superantigen exposure. As colonisation with $S$ aureus in atopic dermatitis is largely confined to cutaneous sites, it is possible that cell mediated rather than antibody responses are important for $S$ aureus eradication in this situation. We postulate that SAG do play a role in the inflammation of atopic dermatitis. Decreased production of INF $\gamma$ in response to $S$ aureus and SAG in atopic dermatitis could reduce eradication of superantigen producing strains of $S$ aureus. Persistence of SAG on the skin would therefore contribute to $\mathrm{T}$ cell activation, production of proinflammatory cytokines and thus to cutaneous inflammation. We have not found evidence to suggest that an inability to make $\operatorname{IgG}$ antibody to SAG is a factor in the development or ongoing inflammatory response of atopic dermatitis.

DE Campbell was supported by an Australian National Health and Medical Research Council Postgraduate Fellowship.

1 Kappler J, Kotzin B, Herron L, et al. V beta-specific stimulation of human $\mathrm{T}$ cells by staphylococcal toxins. Science 1989;244:811-13.

2 Bergdoll MS, Crass BA, Reiser RF, Robbins RN, Davis JP. A new staphylococcal enterotoxin, enterotoxin F, associated with toxic-shock-syndrome Staphylococcus aureus isolates. Lancet 1981;i:1017-21.

3 Evenson ML, Hinds MW, Bernstein RS, Bergdoll MS. Estimation of human dose of staphylococcal enterotoxin A from a large outbreak of staphylococcal food poisoning involving chocolate milk. Int f Food Microbiolol 1988;7:311-

4 Pereira JL, Salzberg SP, Bergdoll MS. Production of staphy-
lococcal enterotoxin D in foods by low-enterotoxinproducing staphylococci. Int F Food Microbiol 1991;14:1925

5 Abe J, Kotzin BL, Jujo K, et al. Selective expansion of T cells expressing T-cell receptor variable regions $\mathrm{V}$ beta 2 and $\mathrm{V}$ beta 8 in Kawasaki disease. Proc Natl Acad Sci U S A 1992; 89:4066-70.

6 Leung DY, Meissner HC, Fulton DR, Murray DL, Kotzin BL, Schlievert PM. Toxic shock syndrome toxin-secreting Staphylococcus aureus in Kawasaki syndrome. Lancet 1993;342:1385-8.

7 Hoeger PH, Lenz W, Boutonnier A, Fournier JM. Staphylococcal skin colonization in children with atopic dermatitis: prevalence, persistence, and transmission of toxigenic and nontoxigenic strains. F Infect Dis 1992;165:1064-8.

8 Leung DY, Harbeck R, Bina P, et al. Presence of IgE antibodies to staphylococcal exotoxins on the skin of patients with atopic dermatitis. Evidence for a new group of allergens. F Clin Invest 1993;92:1374-80.

9 Rosten PM, Bartlett KH, Chow AW. Serologic responses to toxic shock syndrome (TSS) toxin-1 in menstrual and nonmenstrual TSS. Clin Invest Med 1988;11:187-92.

10 Jacobson JA, Kasworm E, Daly JA. Risk of developing toxic shock syndrome associated with toxic shock syndrome toxin 1 following nongenital staphylococcal infection. Rev Infect Dis 1989;11(suppl):S8-13.

11 Luber H, Amornsiripanitch S, Lucky AW. Mupirocin and the eradication of Staphylococcus aureus in atopic dermathe eradication of Staphylococcus au

12 Lever R, Hadley K, Downey D, Mackie R. Staphylococcal colonization in atopic dermatitis and the effect of topical mupirocin therapy. Br f Dermatol 1988;119:189-98.

13 Strange P, Skov L, Lisby S, Nielsen PL, Baadsgaard O. Staphylococcal enterotoxin B applied on intact normal and intact atopic skin induces dermatitis. Arch Dermatol 1996;132:27-33.

14 Campbell DE, Kemp AS. Proliferation and production of interferon-gamma and IL-4 in response to Staphylococcus aureus and Staphylococcal superantigen in childhood atopic dermatitis. Clin Exp Immunol 1997;107:392-7.

15 Lester MR, Hofer MF, Gately M, Trumble A, Leung DY. Down-regulating effects of IL-4 and IL-10 on the IFN-gamma response in atopic dermatitis. F Immunol 1995;154:6174-81.

16 Konig B, Neuber K, Konig W. Responsiveness of peripheral blood mononuclear cells from normal and atopic donors to microbial superantigens. Int Arch Allergy Immunol 1995; 106:124-33. 
17 Reiser RF, Jacobson JA, Kasworm EM, Bergdoll MS Staphylococcal enterotoxin antibodies in pediatric patients from Utah. F Infect Dis 1988;158:1105-8.

18 Christensson B, Hedstrom SA. Serological response to toxic shock syndrome toxin in Staphylococcus aureus infected patients and healthy controls. Acta Pathol Microbio Immunol Scand 1985;93:87-90.

19 Hanifin J, Rajika G. Diagnistic features of atopic dermatitis. Acta Derm Venereol 1980;92(suppl):44-7.

20 Wilson C, Lewis D, Penix L. The physiologic immunodeficiency of immaturity. In: Stiehm E, ed. Immunological disorders in infants and children. Philadelphia: Saunders, 1996:265-8.

21 Loch EG, Crass BA, Bergdoll MS. Staphylococcus aureustoxic shock syndrome toxin-1 antibody titers in serum of German women. Arch Gynecol 1986;237:229-33.

22 Solino NA, da Costa CE, Bergdoll MS. Antibodies to staphylococcal enterotoxins and toxic shock syndrome toxin 1 in sera of patients and healthy people in Rio de Janeiro, Brazil. F Clin Microbiol 1986;24:809-11.

23 Schroder E, Kunstmann G, Hasbach H, Pulverer G. Prevalence of serum antibodies to toxic-shock-syndrome-toxin-1 and to staphylococcal enterotoxins $\mathrm{A}, \mathrm{B}$ and $\mathrm{C}$ in West-Germany. Zentralbl Bakteriol Mikrobiol Hyg [A] 1988 ; 270:110-14.

24 Jacobson JA, Kasworm EM, Crass BA, Bergdoll MS. Nasal carriage of toxigenic Staphylococcus aureus and prevalence of serum antibody to toxic-shock-syndrome toxin 1 in Utah. F Infect Dis 1986;153:356-9.

25 Jacobson J, Kasworm E, Bolte R, HM C. Prevelence of nasa carriage of toxigenic staphylococcus and antibody to toxic shock syndrome toxin-1 in Utah children. Rev Infect Dis 1989;II:324-5.

26 Terai M, Miwa K, Williams T, et al. The absence of evidence of staphylococcal toxin involvement in the pathogenesis of Kawasaki disease. F Infect Dis 1995;172:558-61.

27 Betts Carpenter A. Enzyme linked immunoassays. In: Rose $\mathrm{NR}$, ed. Manual of clinical and laboratory immunology. Washington DC: American Society for Microbiology, 1992:2-9.

\section{Commentary}

Children are never alone: colonised by vast numbers of prokaryotes in the gut, upper airways, and skin, they grow and develop in a sea of microbial activity. Most commensal organisms are not pathogenic, but a number can cause serious illness. Staphylococcus aureus or coagulase positive staphylococcus is one of our oldest commensals. Most newborns have the organism around their healing umbilical stump. This proportion falls to some $30 \%$ in older children with nasal or fingernail carriage. Colonisation increases following skin trauma, burns or the use of occlusive dressings close to the skin. At some time or another we will all have an invasive infection with staphylococci, usually minor, perhaps with the characteristic hallmark of a localised abscess.

Staphylococci also give rise to toxin mediated diseases including food poisoning, toxic shock syndrome, and scalded skin syndrome. Within a genome of some $3000 \mathrm{kB}$, staphylococci may harbour a potential armamentarium of over 10 toxins. Many staphylococcal toxin mediated disorders are mediated by molecules that are particularly effective $\mathrm{T}$ lymphocyte activating agents or superantigens. Nanomolar quantities of these can cause $\mathrm{T}$ cell proliferation.

The clinical significance of these molecules, powerfully demonstrated in the test tube or animal model, has been difficult to assess. ${ }^{2}$ Although devastating at one end of a spectrum with fatal cases of toxic shock syndrome, at the other end most staphylococcal food poisoning probably never presents to medical staff.

General paediatricians encounter staphylococcal superantigens daily in atopic dermatitis. Superantigens are excellent candidates for promoting the inflammatory $\mathrm{T}$ cell infiltrates typical of moderate or severe atopic dermatitis. These molecules produce atopic dermatitis- like lesions if applied to normal skin and in patients recovering from toxic shock syndrome. ${ }^{34}$ Removal of staphylococci and their toxins improves most atopic dermatitis. Surely, therefore, antibodies to the superantigens are protective in this regard? In this useful paper Campbell and Kemp observed that all children were exposed at some point to staphylococcal superantigens (as one might expect with the large environmental reservoir and ubiquity of these organisms). By 16 years of age all their cases had antibodies; however, these did not appear to protect them against atopic dermatitis, or against staphylococcal colonisation. This resembles the situation in adults, in whom the presence of antibodies to staphylococcal cell wall components and toxins and secondary responses do not protect against invasive or toxin-mediated staphylococcal disease. ${ }^{1}$

\section{What are the possible links between staphylococci and allergy?}

Staphylococci frequently infect children with very high levels of IgE, as in Job's syndrome. Their superantigens and protein A (a B cell mitogen) may stimulate IgE production directly, and it is possible that their superantigens switch off or anergise $T$ cells normally involved in preventing allergic responses. Alternatively, by activating regulatory $\gamma \delta \mathrm{T}$ lymphocytes in skin, superantigens may influence local inflammation, a situation observed in contact dermatitis. It is also possible that there is an association between susceptibility to staphylococcal colonisation and allergic disease. The observations made by Campbell and Kemp help begin to dissect the complex relation between staphylococcal superantigens and allergic disease: they demonstrated frequent, early antibody responses to staphylococcal superantigens in healthy children. It seems that staphylococci and their superantigens do not cause allergy in most children, but they are strongly associated with atopic dermatitis in some.

This paper leaves us with two particularly important questions. What determines if and when an individual becomes persistently colonised by staphylococci, if not antibodies-such factors are central to the control of atopic dermatitis. Second, is there a causal relation between staphylococci and atopy in some children, and might one of mankind's oldest colonials be responsible for one of the most common paediatric scourges?

COLIN A MICHIE

Consultant Senior Lecturer in Paediatrics

Ealing Hospital NHS Trust,

Uxbridge Road, London UB1 3HW, UK

1 Mellish ME. Staphylococcal infections. In: Feigin RD, Cherry JD, eds. Pediatric infectious diseases. Philadelphia: WB Saunders and Company, 1992:1240-67.

2 Michie CA, Cohen J. Clinical significance of superantigens. Trends in Microbiology 1998;6:61-5.

3 Michie CA, Cheesbrough J, Wearing A, Davidson S. Atopy in children following shock: a disturbance of the Th1/Th2 equilibrium. Shock 1997;7:141.

4 Herz U, Bunikowsky R, Renz H. Role of T cells in atopic dermatitis. Int Arch Allerg Immunol 1998;115:179-90.

5 Nissen D, Pedersen LJ, Skov S, et al. IgE binding components of staphylococcal enterotoxins in patients with atopic dermatitis. Ann Allerg Asthma Immunol 1997;79: atopic 